\title{
Viva Di Bartini: Eleven New Laws of Conservation Expanding Physics for Global Strategic Management and Strategic Development
}

\author{
Andrei G. Aleinikov (Corresponding author) \\ International Academy of Genius \\ 2231 Segundo Ct., Unit 2, Pleasanton, CA, 94588, USA \\ Tel: 1-831-297-0886 E-mail: dr_andy@academyofgenius.com \\ David A. Smarsh \\ International Academy of Genius \\ 2231 Segundo Ct., Unit 2, Pleasanton, CA, 94588, USA \\ Tel: 1-831-297-0886Ｅ-mail: smarshd@aol.com
}

Received: January 21, 2020 Accepted: February 10, 2020 Published: February 21, 2020

doi:10.5296/bms.v11i1.16505 URL: https://doi.org/10.5296/bms.v11i1.16505

\begin{abstract}
This article illustrates how 11 new Laws of Conservation (Aleinikov, 2004, 2005, 2007a,b,c,d,e; Aleinikov \& Smarsh, 2007, 2009a, 2009b, 2011; Aleinikov \& McFarland, 2008a, 2008b, 2009) expand the Bartini/Kuznetsov LT system of interpretation of laws of physics (Bartini, 1965, 1966, 2005; Kuznetsov \& Bolshakov, 2000), thus expanding the physics and strategic management horizons. The new laws are described, explained, and, in some cases, shown in their application to real world problems, including outer space research and global strategic management issues. However, the main contribution of these discoveries is certainly the opening of new horizons for scientific research - the global strategic development of science. In the history of science, these new laws represent an opportunity for a heuristic leap. While in old times, it took about 50-100 years to discover one new law of conservation, the new approach offered by Robert Oros di Bartini and implemented by our research group, allowed us to discover 11 new laws of conservation within five years. It means 100 times acceleration! That's why this article is titled "Viva di Bartini!" It emphasizes
\end{abstract}


the contribution of the great engineer and scientist, named a "prescient genius" by press, to the strategic development of science, including the first in the world MANAGEMENT SYSTEM FOR LAWS OF CONSERVATION that led to a revolutionary leap in developing new laws and new sciences, including the science of genius - Geniusology, first mentioned in 2003, published in 2004, as described in (Aleinikov, 2013a).

Keywords: Bartini, Laws of Conservation, Bartini Table, strategic management, new laws of conservation

\section{Introduction}

Over history, significant scientific discoveries have advanced the life of society and the understanding of the world around us (Tipler, 1976). The most fundamental of these discoveries are called the laws of conservation. Some of the most well-known laws of conservation include:

- Law of Equal Areas (Kepler - 1609)

- Harmonic Law (Kepler - 1619)

- Law of Conservation of Impulse (Newton - 1686)

- Law of Conservation of Moment of Impulse (Laplace - 1800)

- Law of Conservation of Energy (Mayer - 1842)

- Law of Conservation of Power (Maxwell - 1855).

The laws of conservation have helped science to understand the unity of elements that make up the world as a system. If these elements of the system can be measured and their relationships can be defined, then these measurements and regularities can be applied to real world issues thus resulting in simpler solutions to more and more complex problems.

\section{History of the Issue}

The life of Robert Oros di Bartini (of Italian origins), an outstanding aircraft designer of Soviet era, is certainly of great interest to those who wants to understand his thinking, but it is pretty well-researched; so, we can skip it here. Our interest is science, and here the situation is totally different. For many years after Bartini's death (1974), researchers have been trying to fathom the value of his scientific heritage. Igor Chutko made a great effort in popularizing Bartini's name and pointed at the difficulties he had to go through to publish his scientific article (Chutko, 1978). But some people saw the value of his ideas. Pobisk Kuznetsov - a co-author - continued the development of Bartini's visionary thinking onto modern issues (Kuznetsov \& Bolshakov, 2000). Recognition came very slowly. Many years after his death, the Red Star (Russian central military newspaper) called Robert Oros di Bartini "A Prescient Genius" (Avdeev, 2008). Finally, the English-speaking world received a translation of one Bartini's article - done by Dr. Dmitry Rabunski - the editor-in-chief of the Progress in Physics (Bartini, 1966, Bartini, 2005 [translated by Rabunski]). This was a sign of 
recognition by the West. This translation allowed our research group to attract English-speaking scientists like Drs. Ralucca Gera, David Smarsh (Naval Postgraduate School, Monterey, CA) and some younger generation researchers like Miss Michaela McFarland (Santa Cruz, CA) to explore the depth of Bartini's vision and finally to apply the heuristic power of his breakthrough approach. On the other hand, we need to remember that this discovery is the result of meticulous work that started many years ago in 1983, was first presented to the scientific community in 1987 (Russian Academy of Sciences), and first published as prediction in 1988 (Aleinikov, 1988).

While many of the researchers stated that Bartini's L/T system may be considered a Periodic Table of Laws in Physics like the Mendeleev's Periodic Table of the Elements in Chemistry (Chutko, 1978), none of them tried or managed [and Bushuev (2008) states it directly] to use the Bartini's Table in the manner the Mendeleev's Periodic Table was used - as a heuristic instrument, as a tool for discovery. Just for comparison, Dmitry I. Mendeleev on the basis of his Periodic Table of the Elements predicted the existence of two new chemical elements (two empty cells in his system), and these elements (Germanium and Scandium) were discovered soon after that.

Let us state it again. No one ever used the Bartini's Table for discovering new laws of conservation. No one, except Bartini himself! Both Chutko and P. Kuznetsov mentioned that Bartini discovered a new law of conservation thanks to his Table. The new law was called the Law of Conservation of Mobility. This discovery, in our opinion, not only placed Bartini to the level of such scientists as Kepler, Newton, Mayer, Maxwell, Laplace, etc., but also proved the power of the Table -- the projective power of the Table.

Our task, therefore, was to find the explicit and implicit regularities the Table is based on in order to use these regularities for the discovery of the new laws of conservation. As it was foreseen long ago (Aleinikov, 1988), such an approach could immensely accelerate the scientific progress by showing the path of discovery and helping to see the new horizons of science.

Finally, it happened. Eleven new laws of conservation have been discovered and published in the period 2006-2011 (Aleinikov \& Gera, 2006; Aleinikov, 2007a,b,c,d,e; Aleinikov \& Smarsh, 2007, 2009a, 2009b, 2011; Aleinikov \& McFarland, 2008a, 2008b, 2009). The heuristic power of the Bartini's Table has been proven. And just as every new methodology that brings new scientific results and opens new horizons of research, this new methodology unlocks the door to the future and allows scientists to look further and further.

\section{Description of the 11 New Laws of Conservation}

As is true for all previously discovered and new laws of conservation, these laws work only under the so-called ideal conditions (i.e., when isolated, in isolated environment, in absolute vacuum, under absolute zero temperature, etc.). Therefore, each law states that under unchanging/ideal conditions, the quantity of $\mathrm{X}$ (phenomenon) remains constant. Terms for the new phenomena are introduced through definitions and relations shown to basic units of SI 
units of Joule, Newton, Watt, meter, second. Phenomena, in their turn are defined via their relationship to the other, well-known phenomena, like energy, power, etc.

The eleven new laws of conservation will each be described briefly and then summarized in a table format.

\subsection{Extencia}

The Law of Conservation of Extencia deals with the linear displacement of power. Managing strategic developments like massive deployment of people and material resources requires not only a special kind of thinking (global vision, big picture), but also precise formulas for logistics and, therefore, a solid scientific foundation. To meet these global level calculation needs, Oscar Morgenstern about 70 years ago tried to create a theory of organization (Morgenstern, 1951) while Pobisk Kuznetsov, following the works of La Roche, offered a new branch of economy - physical economy (Kuznetsov - 1980, as shown in, Kuznetsov, Bolshakov, 2000). To help strategic leaders in managing human and material resources, physical economy has already introduced one new unit with the measurements in the range of $L^{6} T^{4}$ (Bartini coined it "Tran") and one new law of conservation with the measurements in the range of $L^{6} T^{6}$. The latter was called the Law of Conservation of Mobility. This new law has been successfully used for transportation problem solving and long-range construction planning. Our proposal was to call the unit of Mobility "Bart" to commemorate the name of the discoverer - Robert Oros di Bartini.

To fill the gap between two measurements $\left(L^{6} T^{-4}\right.$ and $\left.L^{6} T^{-6}\right)$ in the Bartini/Kuznetsov system, we offered a new law of conservation with the measurements in the range of $L^{6} T^{-5}$. A new law of conservation deals with the Conservation of Extension - the term offered for the displacement of power: $E x t=P \times L=E \times L / T=$ const (where Ext is Extencia, $P$ is Power, $E$ is Energy, $L$ is Distance, $T$ is Time). The range of measurement for Extencia is $L^{6} T^{-5}$. A new unit for measuring the Extencia is called Alger (coined from the names of researchers involved in the discovery of the law: Aleinikov + Gera $=$ Alger). ${ }^{*}$ Time and place of discovery: October 16, 2006, Monterey, California.

*Note: Let us state here that the measurement units in Physics are usually named after great scientists (Ampere, Volt, Newton, Joule, Roentgen, etc.), and it is done by the conferences and commissions in order to honor the names of the great researchers. For example, International Electrotechnical Commission in 1930 established the name Hertz (for the unit previously known as cycles-per-second, and it was later adopted by the General Conference on Weights and Measures in 1960. Nowadays, there is the Institute for Reference Materials and Measurements that deals with unit names in Physics. In our specific case, we just understand that if there is a new phenomenon, there must be a new unit to measure it, and we offer a conditional name because the unit cannot exist without a name. It is a necessity.

\subsection{Expancia}

The Law of Conservation of Expancia deals with the expansion of power, area spread of power. 
It is developed on the basis of the previous law - the Law of Conservation of Extencia (extension of power) that described the linear displacement of power. The Law of Conservation of Expancia (expansion of power) states that under ideal/unchanging conditions Expancia (the area spread of power) remains the same, or constant. The mathematical formula of Expancia is the following: $\operatorname{Exp}=\operatorname{Ext} \times L=P \times L^{2}=E \times L^{2} / T=$ const (where Exp is Expancia, Ext is Extencia, $P$ is Power, $E$ is Energy, $L$ is Distance, $T$ is Time. The range of measurement for Expancia is $L^{7} T^{-5}$. A new unit for measuring the Expancia is called Elen to commemorate the memory of Elena Aleinikov who courageously gave 34 year of her life for these laws to be formulated and published. Time and place of discovery: December 4, 2006 (second anniversary of Elena's death), Monterey, California, U.S.A.

\subsection{Volupower}

The Law of Conservation of Volupower deals with Volumetric spread of power. Two previously discovered conservation laws introduced the concepts of Extencia (extension, or linear displacement of power) and Expancia (expansion, or area spread of power), i.e., the one-dimensional and two-dimensional power spread respectfully. The same logic can be applied to three dimensions to describe the volumetric spread of power, Volupower. The Law of Conservation of Volupower states that under ideal/unchanging conditions Volupower (volume spread of power) remains constant. The formula for Volupower is $V l p=P \times L^{3}=$ const (where Vlp is Volupower, $P$ is Power, $L$ is Distance. A new unit for measuring Volupower is called Smar (dedicated to David Smarsh, a co-author of the discovery). Mathematically, 1 Smar $=1$ watt $\times 1 \mathrm{~m}^{3}$. Time and place of discovery of the Law of Conservation of Volupower: August 21, 2007, Monterey, California, U.S.A.

\subsection{Arergation}

The Law of Conservation of Arergation deals with area spread of energy. The term Arergation is derived from area + ergon $=$ area spread of energy. It can be derived from the previously defined Transfer, linear propagation of Energy introduced by Bartini, Kuznetsov, Obraztsova, appr. 1980. The formula for Arergation is Arg $=\operatorname{Trn} \times L=L^{7} T^{-4}=$ const (where Arg is Arergation, Trn is Transfer, $L$ is Distance, and $T$ is Time. The new unit for measuring Arergation is called Sergal. 1 Sergal $=1$ Tran $\times 1 \mathrm{~m}=1 \mathrm{~J} \times 1 \mathrm{~m}^{2}=1 \mathrm{~N} \times 1 \mathrm{~m}^{3}$. Time and place of discovery of the Law of Conservation of Arergation: August 21, 2007, Monterey, California, U.S.A.

\subsection{Volergation}

The Law of Conservation of Volergation deals with volumetric spread of energy. The term Volergation is derived from volume + ergon = volume spread of energy. It can be derived from the Arergation, area spread of energy introduced in the previous law or from Transfer, the linear propagation of energy introduced by Bartini, Kuznetsov, Obraztsova, appr. 1980. The formula for Volergation is $\operatorname{Vrg}=A r g \times L=\operatorname{Tr} n \times L^{2}=L^{8} T^{-4}=$ const (where Vrg is Volergation, Arg is Arergation, Trn is Transfer, $L$ is Distance, and $T$ is Time). The new unit for measuring Volergation is called Kuz (to honor Pobisk Kuznetsov, Bartini's co-author, a great thinker by 
himself). Mathematically, $1 \mathrm{Kuz}=1$ Sergal $\times 1 \mathrm{~m}=1 \mathrm{Tran} \times 1 \mathrm{~m}^{2}=1 \mathrm{~J} \times 1 \mathrm{~m}^{3}$. Time and place of discovery of the Law of Conservation of Volergation: August 21, 2007, Monterey, California, U.S.A.

\subsection{Maneuverability}

The Law of Conservation of Maneuverability deals with displacement of mobility. It can be applied to complex systems like transportation, communication, construction, management and military operations. The concept of Mobility $(M o b)$, introduced by Bartini is measured by $L^{6} T^{-6}$. Maneuverability is mobility over a distance. Maneuverability can also be defined as the rate of Expancia and the velocity or speed of Extencia. Maneuverability can be visualized in military applications. For example, tanks or armored vehicles can cover a certain area based on fuel and weapons. Knowing the characteristics of each, one can predict the potential coverage. Therefore, at a certain moment of time and space, the amount of controlled firepower is constant, or conserved. The term offered for the phenomenon of "Maneuverability" is quite transparent. The range for measurement of Maneuverability is $L^{7} T^{-6}$. The Law of Conservation of Maneuverability states that under ideal/unchanging conditions the rate of expansion of power remains constant. The formula for Maneuverability is $M n v=M o b \times L=E x p / T=E x t \times$ $L / T=$ const (where $M n v$ is Maneuverability, Mob is Mobility, Exp is Expancia, Ext is Extencia, $L$ is Distance, $T$ is Time. A new unit for measuring Maneuverability is called Grig. Mathematically, 1 Grig $=1 \mathrm{watt} \times 1 \mathrm{~m}^{2} / \mathrm{s}$. Time and place of discovery: August 21, 2007, Monterey, California. This law is applicable to all physical as well as complex economic systems and can be a foundation for numerous calculations in strategic management.

\subsection{Operability}

The Law of Conservation of Operability deals with area spread of mobility. Maneuverability was defined above as the rate of expansion. Now, on the next stage, Operability is defined as the linear spread of Maneuverability, or the rate of the Volupower. Operability can be visualized in military applications. For example, military forces can operate in a defined area based on fuel and weapons. The area can also be covered by the air power. Knowing the characteristics of each, one can predict the coverage that will conserve at a certain point of time and space, a certain quantity. At certain moment of time and space, the amount of controlled firepower, or Volupower delivered per unit of time is constant. The term offered for the phenomenon of Operability is quite transparent. The Law of Conservation of Operability states that under ideal/unchanging conditions the rate of Volupower remains constant. The formula for Operability is $O p r=M n v \times L=L^{8} T^{-6}=$ const (where $M n v$ is Maneuverability, $L$ is Distance, $T$ is Time. A new unit for measuring Operability is called Nin. Mathematically, 1 Nin $=1 \mathrm{watt} \times 1 \mathrm{~m}^{3} / \mathrm{s}$. Time and place of discovery: August 21, 2007, Monterey, California.

\subsection{Intensivity}

The Law of Conservation of Intensivity deals with the rate of maneuverability. The term offered for the phenomenon of Intensivity should be different from the word "intensity" since the latter has already been used in Physics (for example, as intensity of the light flow, with the 
measurement in the range of $L^{3} T^{-5}$ and the unit name Lumen). The Law of Conservation of Intensivity states that under ideal/unchanging conditions the rate of maneuverability remains constant. The formula for Intensivity is Int $=M n v: T=L^{7} T^{-7}=$ const (where Int is Intensivity, $M n v$ is Maneuverability, $L$ is Distance, $T$ is Time. A new unit for measuring Intensivity is called Rabun (to honor Dr. D. Rabunski who had the courage to translate an extremely complex Bartini's article to English thus discovering it for the English-speaking world). Mathematically, 1 Rabun $=1 \mathrm{Grig}: 1 \mathrm{~s}=1$ Bart $\times 1 \mathrm{~m}: 1 \mathrm{~s}$. Time and place of discovery: August 21, 2007, Monterey, California. The most recent publication - July, 2011 (Aleinikov \& Smarsh, 2011).

It is important to note here that the concept of Intensivity (both the phenomenon and the term) to a certain extent highlights the whole block of new laws and returns the researchers to the "basic" truth - the fact that the entire moving matter (world) has two major aspects: organization of movement (studied by Organizology) and the intensity of movement (studied by Intensiology). Those two new sciences have been also predicted and offered on the basis of Bartini’s Table (Aleinikov, 2004; Aleinikov \& Gera, 2006).

\subsection{Flexivity}

The Law of Conservation of Flexivity deals with the rate of operability. The term offered for the phenomenon of Flexivity should be different from the word "flexibility" widely used in non-science. The Law of Conservation of Flexivity states that under ideal/unchanging conditions the rate of operability remains constant. The formula for Flexivity is Fle $=$ Int $\times L=$ $L^{8} T^{-7}=$ const (where Fle is Flexivity, Int is Intensivity, $L$ is Distance, $T$ is Time). A new unit for measuring Flexivity is called Nikkon. Mathematically, 1 Nikkon $=1$ Rabun $\times 1 \mathrm{~m}=1 \mathrm{Nin}: 1 \mathrm{~s}$. Time and place of discovery: August 21, 2007, Monterey, California.

\subsection{Flow}

The Law of Conservation of Flow (rate of mass change, russ. расход массы) as opposed to the previous nine laws, is expanding the system of conservation laws in another direction. We certainly understand that there is a lot of research in this field. However, yet there is no conservation law formulated for this group of phenomena. The new law deals with the cell in the Table that is the closest cell to the mass, and the latter is considered to be the central cell because it includes the Law of Conservation of Mass/Matter (Lavoisier, Lomonosov). The mathematical formula of Flow is the following: Flo $=m / t=$ const (where Flo is Flow, $m$ is mass, and $t$ is Time. The range of measurement for Flow is $L^{3} T^{-3}$. A new unit for measuring the Flow is called Mim (coined from the first and the last name of one of the discoverers, Michaella McFarland). Time and place of discovery: February 23, 2008, Felton (Santa Cruz), California.

\subsection{AcceFlow}

The Law of Conservation of AcceFlow (acceleration of flow, or acceleration of mass change, the square rate, or the rate of the rate of mass change), as the 11th law, is based on the 10th Law of Conservation - the Law of Conservation of Flow, specifically described in Aleinikov \& McFarland (2008a). The new law - the Law of Conservation of AcceFlow fills the cell in the 
Bartini's Table that is located above the Law of Conservation of Flow - second cell up from the cell of Mass. The mathematical formula of Conservation of AcceFlow is the following: Afl = Flo $t=m / t^{2}=$ const (where Afl is AcceFlow, Flo is Flow, $m$ is Mass, and $t$ is Time). The range of measurement for AcceFlow is $L^{3} T^{-4}$. A new unit for measuring the AcceFlow is called Elim (coined from the mother's name of one of the discoverers - Elizabeth McFarland). Time and place of discovery: February 2, 2009, Felton (Santa Cruz), California.

\subsection{All eleven.}

Here is a list of the new laws that includes the name of phenomena, its abbreviation, mathematical formula with the relationship to other phenomena, range of measurements, and the unit name.

1. Extencia, extension, or linear displacement of power, $(E x t)=P \times L=L^{6} T^{-5}$ (Alger)

2. Expancia, expansion, or area spread of power, $($ Exp $)=E x t \times L=L^{7} T^{-5}$ (Elen)

3. VoluPower, three-dimensional volumetric spread of power, $(V l p)=\operatorname{Exp} \times L=$ $L^{8} T^{-5}($ Smar $)$

4. Arergation, area spread of energy, $($ Arg $)=\operatorname{Tr} n \times L=L^{7} T^{-4}($ Sergal $)$

5. Volergation, volumetric spread of energy, $(\mathrm{Vrg})=\operatorname{Arg} \times L=L^{8} T^{-4}(\mathrm{Kuz})$

6. Maneuverability, displacement of mobility (the latter discovered by Bartini) (Mnv) $=M o b \times L=L^{7} T^{-6}($ Grig $)$

7. Operability, area spread of mobility, $(\mathrm{Opr})=\mathrm{Mnv} \times L=L^{8} T^{-6}$ (Nin)

8. Intensivity, rate of maneuverability, (Int) $=M n v: t=L^{7} T^{-7}$ (Rabun)

9. Flexivity, rate of operability, $(F l x)=I n t \times L=L^{8} T^{-7}$ (Nikkon)

10. Flow, rate of mass change, $($ Flo $)=m / t=L^{3} T^{-3}(\mathrm{Mim})$

11. AcceFlow, acceleration of flow, $(A f l)=$ Flo $: t=m / t^{2}=L^{3} T^{4}($ Elim $)$

\subsection{Table}

To make the broadening Physics horizons visualized, here is the resulting Table (see Figure 1). The blue axes are Time and Distance to the power of zero and from zero - to the power of integers. The green cells like Velocity and Acceleration are concepts everyone knows, but one day in the past, there was some scientist who discovered them (the Table offers place in the matrix and measurements for many of them, but we omit them here for simplicity). The other green cells represent laws of conservation. For example, it was Kepler who discovered the Law of Equal Areas (in 1609) and Harmonic Law (in 1619). Lavoisier and Lomonosov 
discovered the Law of Conservation of Mass / Matter. Newton formulated the Law of Conservation of Impulse (in 1686). Mayer discovered the Law of Conservation of Energy (in 1842). Laplace discovered the Law of Conservation of Moment of Impulse (in 1800). Maxwell stated the Law of Conservation of Power (in 1855). Bartini developed the Law of Conservation of Mobility, the unit of which we offered to name Bart to honor Bartini - the discoverer. Then Bartini offered a unit (Tran) for what we completed the next law -- as the Law of Conservation of Transfer. The yellow-marked cells represent new laws of conservation discovered and described by our research group.

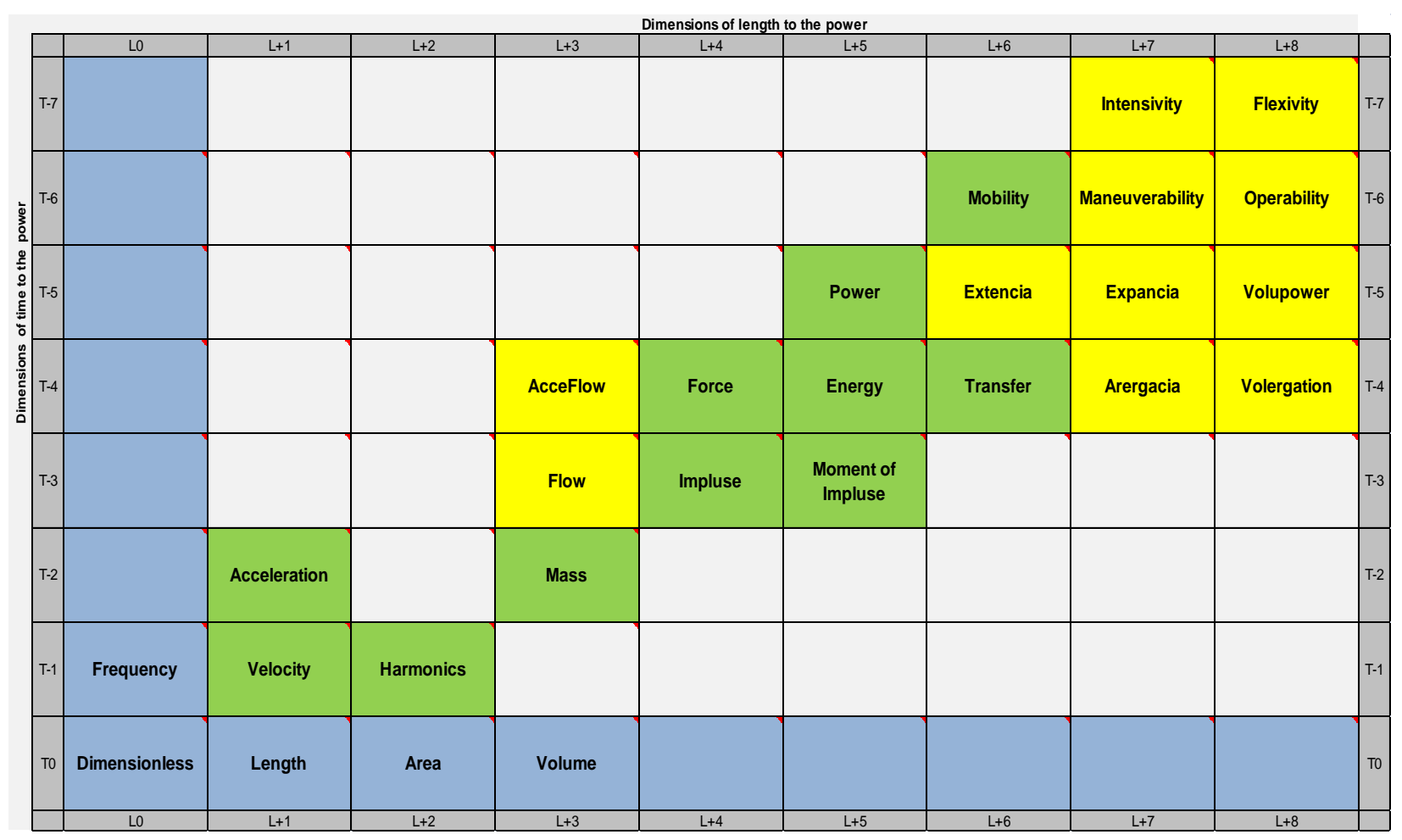

Figure 1. Matrix of Physical Laws and Measurements.

These new laws are applicable to such complex systems as transportation, communication, construction, management and military operations. They also apply to many other physical as well as economic systems and become a foundation for numerous calculations in strategic management. Below are some examples of the laws application.

\section{Application Examples and Ideas}

The new laws of conservation open new horizons for researchers as well as for logistics and strategic management specialists around the world. Some of them have already been applied to solving practical problems. The others are still waiting for new researchers and grants. One thing must be stated, however, at once. Just as the Law of Conservation of Mobility and the new unit Tran, discovered by Bartini, helped the Soviets to correctly calculate the labor (and pay) in transportation systems, the new laws offer new solutions in their fields. Their application is a huge program of future research, but we can share some modern results. 


\subsection{The Law of Conservation of Extencia}

The Law of Conservation of Extencia was applied to the explanation of athletics, construction, military, transportation, information systems, electricity and heat consumption, as well as communication. By its pure existence, it helped students, teachers, and researchers to see numerous phenomena of the world as one essence. This is the economy of brain energy (Aleinikov, 2007a,b,c,d,e,f).

\subsection{The Law of Conservation of VoluPower}

The Law of Conservation of Volupower has been applied to the analysis of the radar that forms a three-dimensional dome within which it can detect targets. Characteristics of the atmosphere and the radar will result in the varying size of the dome. Depending on these factors, each radar has a potential to cover a certain volume - effective coverage zone (in old terms) and VoluPower in new terms.

Another use of the Law of Conservation of VoluPower was to describe the potential for cloud formation. The formation of cloud droplets is dependent on several factors including heat, moisture and the environment. Therefore, each cloud will have a potential to reach a certain volume that can be determined from these factors. If these relationships are defined, then as in the radar case above, VoluPower can describe these relationships and be measured.

Then the concept of VoluPower was applied for the analysis of nation states as a Global Power Descriptor. The hypothesis is that the overall sum of the parts of the compared nation-state systems can be used for calculating the strength/weakness thus predicting the global trends of power changes. For example, the calculation can show when the VoluPower of a nation-state like China will exceed that of the United States.

Finally, the concept of VoluPower was applied to the Nuclear Weapons as a subset of the nations' military power overall. Assessing nuclear VoluPower of nation states provides a measurement of potential that leaders can use to determine risk factors. Our approach allows researchers (and leaders of all ranks) to generalize and visualize the volume of power. This gives a simple vision to complex (and often overcomplicated) comparisons filled by disconnected, unsystematic, and over excessive data. Thus, the Law of Conservation of VoluPower and its social-political application can become an instrument of controlling and influencing the future in strategic management and strategic development (Smarsh \& Aleinikov, 2007, 2008a,b,c, as well as Aleinikov \& Smarsh 2009a,b, 2011).

\subsection{The Law of Conservation of Flow}

The Law of Conservation of Flow was applied to the Pioneer anomaly. It's common knowledge that Pioneer 10 \& Pioneer 11 spacecraft on the outskirts of the solar system were detected with an anomalous location error. Calculations showed that spacecraft experienced a slight velocity decrease - a deceleration. Since no explanation was available, the anomalous behavior was named the Pioneer anomaly, Pioneer effect, or Pioneer acceleration. The available hypotheses attempting to explain the effect included: 
- Pressure of the solar radiation on the spacecraft

- The solar wind

- The solar corona perturbation

- Electromagnetic forces

- Stability (or rather instability) of the references of atomic clocks, or battery leakage

- The gravity of the Kuiper Belt

- ...or black holes, totally unknown matter and the necessity of New Physics.

Despite a number of hypotheses offered for the explanation of the Pioneer anomaly, T. Malik in 2007 stated that the NASA's Great Gravity Mystery still remains unsolved.

Then a young researcher, M. McFarland offered her hypothesis: it is the interplanetary outer space "vacuum," or rather the Hyper Low Density Gas (HLDG), that decelerates the space ships moving in this FLOW.

Her discovered Law of Conservation of Flow takes this seemingly miniscule flow into account and demonstrates that this flow will resist the movement of Pioneer 10 and 11. The constant bombardment of the surface of the spacecraft will result in the negative acceleration, considered to be "an anomaly." Just as the flow of air in the atmosphere decelerates the flying aircraft, the HLDG flow can decelerate the spacecraft. The HLDG has the following characteristics:

- Interplanetary space contains 10 molecules per $\mathrm{cm}^{3}$

- Interstellar space contains 1 molecule per $\mathrm{cm}^{3}$

- Intergalactic space contains $10^{-6}$ molecules per $\mathrm{cm}^{3}$.

A simple multiplication of HLDG density (10 molecules per cubic $\mathrm{cm}$ ) to the number of square centimeters in the area of the Pioneer spacecraft (about $6,600 \mathrm{~cm}^{2}$ ) and to the number of centimeters in the covered flight path $(12,000,000,000 \mathrm{~km} \times 1000$ meters $\times 100 \mathrm{~cm}=12 \mathrm{x}$ $10^{14}$ ) gives us a staggering number of about $8 \times 10^{18}$ molecules that hit the craft. The speed of this "bombardment" ranged from 8 to $17 \mathrm{~km}$ per second. So, every second of the flight, every minute of the flight for many years, there was the combined force acting against the flying spacecraft.

The researcher offered a simple test. A model of the Pioneer 10 spacecraft, or just a cardboard cut (loaded to the same mass) could be exposed to the flow of Hydrogen or any gas (calculated to the equivalent mass of $8 \times 10^{18}$ molecules of Hydrogen) with the speed of 8-17 $\mathrm{km} / \mathrm{s}$ (or the equivalent of the lower speed but longer duration). When calculations and testing are complete, the "anomaly" will be explained. 
Thus, there will be no need to create another spacecraft and send it to the outskirts of the Solar system, which will save billions of dollars to the taxpayers. Obviously, this is a big plus in strategic management and strategic development.

In addition to this economic gain, the new Law of Conservation of Flow may also save modern physics from the "necessity of the new physics" (Occam's razor). The classical physics is far from being exhausted. The new laws of conservation and the discovery of how to make new discoveries are the proof (Aleinikov \& McFarland, 2008a, 2008b, 2009).

\section{Conclusion}

This article updates the results in the process of discovery of the eleven new laws of conservation built on the Bartini/Kuznetsov LT system of presenting the laws of Physics. All new conservation laws are applicable to technical, military, transportation, communication, economic and other complex systems requiring scientific foundations for global strategic management and strategic development solutions. Understandably, this short article is of general character, and all laws presented above will be described, explained, and shown in their further application to reality in the forthcoming publications. It is absolutely obvious, however, that these new laws open new horizons for researchers as well as for logistics and strategic management specialists around the world. Moreover, they show how a new tool (methodology) in science can give advantage to the people and the country that developed it. The new laws of physics, the new sciences and models - that's what truly is a highly advanced strategic development, and this development became possible thanks to the discovery of Robert Oros di Bartini - a true prescient genius whose vision, when applied correctly, leads to new, earlier unthinkable, achievements. For example, studying the content of the Table led to the discovery of the new laws of physics, but studying the structure of the Table led to the introduction of new sciences, like Sozidonics, the science of creativity, mentioned first in 1991 and published later (Aleinikov, 1994, 2013c), Novology, the science of newness, first mentioned in 1991, then published in several articles (Aleinikov, 2002, 2013b), Organizology and Intensiology (Aleinikov, 2004, 2005) and even Geniusology, the science of genius, first mentioned in 2003, published in 2004, but described in detail in (Aleinikov, 2013a) - all of them, thanks to Bartini. Viva di Bartini!

\section{Acknowledgement}

The authors express deep gratitude to everybody who took part in the discussion, development, refinement, critic, and editing of the new laws and concepts, starting from the Russian Academy of Sciences, Moscow, and finishing at the Naval Postgraduate School, Monterey, California, U.S.A.

\section{References}

Avdeev, J. (2008). Prescient genius, red star. (russ. Ю. Авдеев, (2008), Гений предвидения, "Красная звезда".) [Online] Available: 
http://www.redstar.ru/2008/01/23_01/4_01.html (October 22, 2010).

Aleinikov A. G. (1988). Об эвристичности акта коммуникации и моделирования [On heuristic aspects of communication and modeling acts], Языковое сознание: Стереотипь и творчество [Language awareness: stereotypes and creativity] (pp. 55-76). Moscow: Russian Academy of Sciences Institute of Linguistics.

Aleinikov A. G. (1994). Sozidolinguistics for creative behavior. The Journal of Creative Behavior. 28 (2). 107-123. [Online]. Available: https://dx.doi.org/10.1002/j.2162-6057.1994.tb00724.x (February 08, 2020).

Aleinikov A. G. (2002). Novology, the science of newness, for creativity and innovation research. In A. Aleinikov (Ed.) The future of creativity (pp. 113-141). Bensenville, IL: Scholastic Testing Services, Inc.

Aleinikov A. G. (2004). Organizology, new science of organization: A breakthrough in scientific explanation of the world. Proceedings of the spring international conference, Allied Academies international conference, Maui, HI.

Aleinikov A. G. (2005). Organizology: The main unit of measurement for the new science. Proceedings of the spring international conference, Allied Academies international conference, Memphis, TN.

Aleinikov A. G. (2007a). The conservation of extension: New law of conservation. Proceedings of the summer 2007 international internet conference, Allied Academies international conference.

Aleinikov A. G. (2007b). Nine new laws of conservation: Future science horizons, In Proceedings of the Academy of strategic management (Vol 6, Number 2, pp. 5-9), Allied Academies international conference. Reno, NV.

Aleinikov, A. G. (2007c). The conservation of Expancia: Second law of conservation. Proceedings of the Academy of strategic management (Vol 6, Number 2, pp. 1-3), Allied Academies international conference, Reno, NV.

Aleinikov, A. G. (2007d). The conservation of Expancia: A new law of conservation. Journal of Economics and Economic Education Research. 8 (3). 49-65.

Aleinikov, A. G. (2007e). The conservation of extension: A new law of conservation. Proceedings of the Academy of strategic management (Vol 6, Number 1, p. 3), Allied Academies International Conference, Jacksonville, FL.

Aleinikov, A. G. (2013a). Genius. In Encyclopedia of creativity, invention, innovation, and entrepreneurship (pp. 790-805). NY: Springer.

Aleinikov, A. G. (2013b). Novology. In Encyclopedia of creativity, invention, innovation, and entrepreneurship (pp. 1392-1400). NY: Springer. 
Aleinikov, A. G. (2013c). Science of Creativity. In Encyclopedia of creativity, invention, innovation, and entrepreneurship (pp. 1574-1592). NY: Springer.

Aleinikov, A. G., \& Gera, R. (2006). Mathematical predictions of organizology, the new science of organization. Proceedings of the fall 2006 international conference, Allied Academies international conference, Reno, NV.

Aleinikov, A. G., \& McFarland, M. (2008a). The conservation of flow: tenth law of conservation. Proceedings of the Academy of strategic management (Vol 7, Number 1, pp. 1-3), Allied Academies International Conference, Tunica, MS.

Aleinikov, A. G., \& McFarland, M. (2008b). The great NASA gravity mystery - solved!, Proceedings of the Academy of strategic management (Vol 7, Number 2, pp. 1-3) Allied Academies international conference, Reno, NV.

Aleinikov, A. G., \& McFarland, M. (2009). The conservation of AcceFlow: Eleventh law of conservation. Proceedings of the Academy of strategic management, Allied Academies international conference, New Orleans, LA.

Aleinikov, A. G., \& Smarsh, D. A. (2007). Volumetric conservation of power: Volupower. Proceedings of the international fall conference, Allied Academies, Reno, NV.

Aleinikov, A. G., \& Smarsh, D. (2009a). The conservation of maneuverability. Proceedings of the Academy of strategic management ( $\mathrm{Vol}$ 8, Number 1, p. 10), Allied Academies international conference, New Orleans, LA.

Aleinikov, A. G., \& Smarsh, D. (2009b). The law of conservation of operability. Proceedings of the Academy of strategic management (Vol 8, Number 2, p. 1), Allied Academies international conference, Las Vegas, NV.

Aleinikov, A. G., \& Smarsh, D. A. (2011). Law of conservation of intensivity. Proceedings of the summer 2011 international internet conference, Allied Academies international conference.

Bartini, R.O. di. (1965). Некоторые соотношения между физическимии константами. [Some relations between the physical constants], Доклады Академии наук СССР [Reports of the USSR Academy of Sciences] (163 (4). pp. 861-864), Moscow.

Bartini, R.O. di. (1966). Соотношение между физическими величинами. [Relations between the physical measurements], Проблемь теории гравитации и элементарных частии [Problems of theory of gravitation and elementary particles] (pp. 249-266). Moscow: Atomizdat.

Bartini, R.O. di (2005). Relations between the physical constants (translated by D. Rabunski). Progress in Physics, 3, 34-40.

Bushuev, A. (2008). Mathematics, TRIZ, Bartini, and something else (russ. Бушуев, A. Математика, ТРИЗ, Бартини и кое-что еще) In Metodolog.ru. [Online]. Available: 
http://www.metodolog.ru/01277/01277.html (July 13, 2011).

Chutko, I. (1978). Red aircraft. Moscow: Political Literature. (russ. И. Чутко "Красныле самолётьл". М. Изд. полит. литературы)

Kuznetsov O. L., \& Bolshakov, B. E. (2000). Kuznetsov P.G. and the problem of sustainable development of the humanity in the system nature-society-man. (russ. О. Л. Кузнецов, Б. Е. Большаков. П. Г. Кузнецов и проблема устойчивого развития Человечества в системе “природа-общество-человек”. 2000) [Online]. Available:

http://www.pobisk.narod.ru/Pr-ob-ch/001.htm (February 05, 2020)

Morgenstern O. (1951). Prolegomena to a theory of organization. [Online]. Available: https://www.mises.at/static/literatur/Artikel/morgenstern-prolegomena-to-a-theory-of-organiz ation.pdf (February 05, 2020)

Smarsh, D., \& Aleinikov, A. G. (2007). Volumetric conservation of power: Volupower. Proceedings of the Academy of strategic management (Vol 6, Number 2, pp. 11-12), Allied Academies fall 2007 international conference, Reno, NV.

Smarsh, D., \& Aleinikov, A. G. (2008a). Applying the law of conservation of Volupower to global analysis of nation-states. Proceedings of the Academy of strategic management (Vol 7 , Number 1, pp. 5-6), Allied Academies international conference, Reno, NV.

Smarsh, D., \& Aleinikov, A. G. (2008b). The law of conservation of Volupower applied as a nation-state global power descriptor. Proceedings of the Academy of strategic management, Vol 10, pp. 109-111), Allied Academies international internet conference.

Smarsh, D., \& Aleinikov, A. G. (2008c), The law of conservation of Volupower applied to a global nuclear weapons tenet. Proceedings of the Academy of strategic management, (Vol 15, Number 2, pp. 362-363), Allied Academies international conference, Reno, NV.

Tipler, P. A. (1976). Physics (392-394, 944-951). New York, NY: Worth Publisher.

\section{Glossary}

AcceFlow: acceleration of flow.

Arergation: area spread of energy.

Expancia: expansion, or area spread of power.

Extencia: extension, or linear displacement of power

Flexivity: rate of operability.

Flow: rate of mass change.

Intensivity: rate of maneuverability. 


\section{Macrothink}

Maneuverability: displacement of mobility (the latter discovered by Bartini).

Operability: area spread of mobility

Volergation: volumetric spread of energy.

VoluPower: three-dimensional volumetric spread of power.

\section{Copyright}

Copyright for this article is retained by the author(s), with first publication rights granted to the journal.

This is an open-access article distributed under the terms and conditions of the Creative Commons Attribution license (http://creativecommons.org/licenses/by/4.0/). 